\title{
Impaired exercise ventilatory efficiency in smokers with low transfer factor but normal spirometry
}

\author{
To the Editor:
}

It has long been established that severe decrements in transfer factor for carbon monoxide (TLCO) are associated with negative outcomes in patients with chronic obstructive pulmonary disease (COPD), including exertional hypoxaemia and poor exercise tolerance [1]. More recently, exercise capacity has been found to be diminished in smokers both with and without airflow limitation, with mild-to-moderate decrements in TLCO [2-4]. The mechanisms that link reduced TLCO to low exercise capacity in smokers without COPD, even in the absence of increased hypoxic drive or overtly abnormal lung mechanics remain unknown.

It is noteworthy that a low TLCO has been linked to structural markers of early emphysema [5] and pulmonary microvascular abnormalities [6] in smokers with airflow limitation but preserved forced expiratory volume in $1 \mathrm{~s}$ (FEV1), i.e. Global Initiative for Chronic Obstructive Lung Disease (GOLD) stage 1. Such abnormalities are well known causes of increased "wasted" ventilation in the physiological dead space. Interestingly, increased activity-related dyspnoea and impaired exercise capacity in these subjects have been associated with an increased ventilation $\left(V^{\prime} \mathrm{E}\right)$-carbon dioxide output $\left(V^{\prime} \mathrm{CO}_{2}\right)$ relationship, i.e. poor ventilatory efficiency. Thus, an excessive ventilatory response to exertion, likely to compensate for increased physiological dead space, led the patients to reach their mechanical and sensory limits at lower exercise intensities [7-9].

In this context, we wondered whether similar mechanisms would be present in smokers without airflow limitation but impaired TLCO. We specifically tested the hypotheses that these subjects would present with poorer ventilatory efficiency, which in turn, would be associated with greater exertional breathlessness and lower exercise capacity compared to their counterparts with preserved TLCO. Confirmation of these premises would provide novel evidence that ventilatory inefficiency is the missing link between low TLCO and poorer exercise tolerance in smokers $[2,3]$.

We therefore assessed 15 current smokers who failed to fulfil any spirometric criteria for airflow limitation (FEV1/forced vital capacity (FVC) ratio, FEV1 and forced expiratory flow at $25-75 \%$ of FVC all above the lower limit of normal), but presented with single-breath TLCO below the lower limit of normal $(71.2 \pm 9.3 \%$ predicted). The subjects were carefully matched by age, gender, body weight, level of regular physical activity and smoking history $(\mathrm{p}>0.05)$ to 15 smokers with preserved spirometry and normal TLCO (95.3 $\pm 10.5 \%$ predicted). Subjects were asked to refrain from smoking during the preceding $4 \mathrm{~h}$. Exercise ventilatory efficiency in response to incremental ramp cardiopulmonary exercise testing (CPET) was determined by the $V^{\prime} \mathrm{E}-V^{\prime} \mathrm{CO}_{2}$ slope and the $V^{\prime} \mathrm{E} / V^{\prime} \mathrm{CO}_{2}$ ratio nadir [7-9].

A maximal exercise test was performed by all subjects, as indicated by the peak respiratory exchange ratio $>1.10$ in both groups $(1.14 \pm 0.03$ versus $1.16 \pm 0.04$ for low and normal TLCO groups, respectively; $\mathrm{p}>0.05)$. In line with our hypothesis, the low TLCO group presented with lower peak $\mathrm{O}_{2}$ uptake compared to the normal TLCO group $\left(1384 \pm 429 \mathrm{~mL} \cdot \mathrm{min}^{-1}\right.$ versus $1676 \pm 436 \mathrm{~mL} \cdot \mathrm{min}^{-1}$; $\left.\mathrm{p}<0.05\right)$. No subject presented with exercise-induced $\mathrm{O}_{2}$ desaturation based on the results of pulse oximetry (peak values $\geqslant 94 \%$ ). Regardless of the chosen metric, the low TLCO group presented with greater exertional ventilation than their counterparts with preserved TLCO $\left(V^{\prime} \mathrm{E}-V^{\prime} \mathrm{CO}_{2}\right.$ slope $28.3 \pm 2.3$ versus $26.2 \pm 2.7$ and $V^{\prime} \mathrm{E} / V^{\prime} \mathrm{CO}_{2}$ nadir $29.5 \pm 3.1$ versus $27.5 \pm 2.0$, respectively; $\mathrm{p}<0.05$ ) (figure $1 \mathrm{a}$ ). As shown in figure $1 \mathrm{~b}$, this trend was associated with a consistent downward shift in end-tidal $\mathrm{CO}_{2}$. Despite greater inspiratory constraints in the low TLCO group,

@ERSpublications

Ventilatory inefficiency in non-COPD smokers is associated with lower exercise capacity http://ow.ly/Mf7n308Qm5M

Cite this article as: Walter Barbosa G, Neder JA, Utida K, et al. Impaired exercise ventilatory efficiency in smokers with low transfer factor but normal spirometry. Eur Respir J 2017; 49: 1602511 [https://doi.org/ 10.1183/13993003.02511-2016]. 

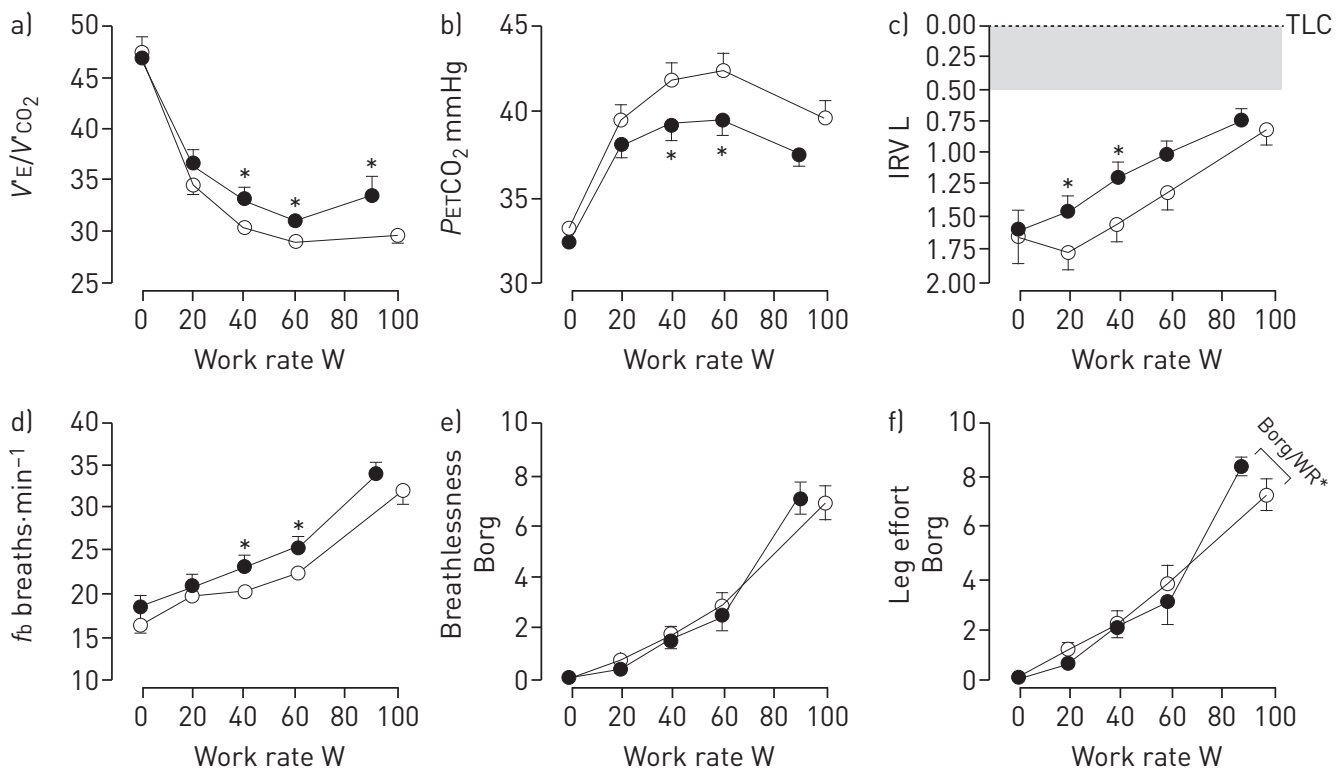

FIGURE 1 Key physiological and sensory responses to incremental cardiopulmonary exercise testing in smokers with normal spirometry presenting (closed symbols) or not presenting (open symbols) with low resting transfer factor for carbon monoxide ( $T$ LCO). The low TLCO group showed a) poorer ventilatory efficiency, b) lower end-tidal $\left.\mathrm{CO}_{2}\left(\mathrm{PETCO}_{2}\right), \mathrm{c}\right)$ greater inspiratory constraints and $\left.d\right)$ higher respiratory frequency $\left(f_{\mathrm{b}}\right)$ than their counterparts with preserved $T$ LCO. el Exertional dyspnoea scores showed no differences between groups. f) Peak leg effort/ work rate however, was significantly higher in the low TLCO group. * ${ }^{*}<<0.05$. $V^{\prime} E$ : minute ventilation; $V^{\prime} \mathrm{CO}_{2}$ : carbon dioxide output; IRV: inspiratory reserve volume; TLC: total lung capacity; WR: work rate.

neither group reached a critically low inspiratory reserve volume $(\sim 0.5 \mathrm{~L}$; shaded area in figure 1c) [8]. Greater exercise ventilation was related to high respiratory frequency at a given work rate (figure 1d). However, there were no significant differences in Borg dyspnoea scores at iso-work rate or peak exercise (figure 1e; $\mathrm{p}>0.05$ ).

The results herein presented support the assertion that CPET can be clinically useful to uncover subtle gas exchange-ventilation coupling abnormalities before the appearance of resting airflow limitation in smokers. More specifically, those with low TLCO ventilated in excess of the prevailing metabolic demand, $i$. $e$. they had poorer exertional ventilatory efficiency (figure 1a). Early emphysema [5], ventilation distribution heterogeneity [10] and pulmonary microvascular disease [6], in different combinations, could explain these findings, particularly in subjects susceptible to the deleterious effects of smoking. The physiological basis of these derangements likely stem from increased dead space per se rather than a small tidal volume [11]. In fact, external dead space predictably increased $V^{\prime} \mathrm{E} / V^{\prime} \mathrm{CO}_{2}$ in mild COPD [8]. Under-perfusion of relatively well-ventilated alveoli is known to dilute expired $\mathrm{CO}_{2}$, leading to low end-tidal $\mathrm{CO}_{2}$ (figure 1b) [11]. Additional studies to investigate the structural correlates of a low TLCO in this specific sub-population of smokers are warranted.

Contrary to our expectations however, we were unable to ascertain a causative role of impaired ventilatory efficiency in worsening exertional dyspnoea in smokers with low TLCO. As shown in figure 1c, these subjects presented with slightly increased inspiratory constraints than their counterparts with preserved TLCO. These abnormalities however, were rather modest and a "safe" inspiratory reserve volume was maintained throughout exercise in both groups. In other words, critical mechanical constraints were not reached, which was likely a consequence of relatively large resting reserves and a lack of substantial dynamic hyperinflation in subjects without expiratory flow limitation [7-9]. These findings explain the close similarity between exertional dyspnoea scores in both groups (figure 1e).

If poor ventilatory efficiency per se did not play a central role in reducing exercise capacity, why did subjects with low TLCO stop exercising earlier than their counterparts? The low TLCO group tended to present with a lower peak heart rate $(137 \pm 14 \mathrm{bpm}$ versus $146 \pm 18 \mathrm{bpm})$ and peak $\mathrm{O}_{2}$ pulse $\left(10.4 \pm 3.3 \mathrm{~mL} \cdot\right.$ beat $^{-1}$ versus 11.3 $\pm 2.4 \mathrm{~mL} \cdot$ beat $\left.^{-1}\right)$; moreover, as shown in figure $1 \mathrm{f}$, they showed significantly greater peak work rate-corrected leg effort scores $(\mathrm{p}<0.01)$, i.e. a cardio-circulatory-muscular pattern of abnormalities [12]. It seems unlikely that the observed mild-to-moderate decrements in TLCO could be attributed to pulmonary 
vascular abnormalities that were sufficiently severe to impair central haemodynamics. A more reasonable hypothesis relates to the potential role of a low TLCO in signalling greater systemic endothelial and/or microvascular abnormalities in subjects with higher susceptibility to the pro-inflammatory and oxidative consequences of smoking [13, 14]. For instance, in a large population-based study, GLÄsER et al. [15] found that impaired peripheral endothelial function and reduced flow-mediated dilation was associated with lower TLCO in smokers. Moreover, smoking can be associated with capillary rarefaction and mitochondrial dysfunction $[13,14]$, which in association with impaired vascular control [15], could impair muscle $\mathrm{O}_{2}$ delivery and utilisation. In this context, a low TLCO might serve as a marker of more extensive systemic microvascular dysfunction, the deleterious consequences of which are magnified under the stress of exercise, i.e. when $\mathrm{O}_{2}$ demands are increased. In fact, low TLCO was associated with a low TLCO/alveolar volume (VA) ratio $\left(3.9 \pm 0.6 \mathrm{~mL} \cdot \mathrm{min}^{-1} \cdot \mathrm{mmHg}^{-1}\right.$ versus $\left.4.7 \pm 0.4 \mathrm{~mL} \cdot \mathrm{min}^{-1} \cdot \mathrm{mmHg}^{-1} ; \mathrm{p}<0.01\right)$ but similar VA $(5.0 \pm 1.1 \mathrm{~L}$ versus $5.4 \pm 1.1 \mathrm{~L} ; \mathrm{p}>0.05)$. Thus, decrements in TLCO seem more likely related to pulmonary microvascular abnormalities than impaired gas distribution. These considerations call for future investigations linking smoking-related impairments in pulmonary and peripheral microvasculature before the phenotypical exteriorisation of COPD.

In conclusion, unexpected decrements in TLCO in smokers with normal spirometry are associated with excessive exercise ventilation and lower exercise capacity. If subsequent investigations confirm our theory that a low TLCO is indicative of coexistent peripheral microvascular abnormalities, these subjects might benefit from early interventions to improve muscle $\mathrm{O}_{2}$ delivery and utilisation, e.g. exercise training. Considering the mounting evidence that poor ventilatory efficiency increases exertional breathlessness once airflow limitation ensues [7-9], smokers with low TLCO might be at greater risk of progression to the symptomatic stages of COPD. In addition to the imperative of smoking cessation, it is recommended that this specific subgroup of smokers be more closely followed-up for early detection of activity-related breathlessness and its ominous consequences.

Gisele Walter Barbosa ${ }^{1}$, J. Alberto Neder ${ }^{2}$, Karina Utida ${ }^{1}$, Denis E. O’Donnell ${ }^{2}$ and Paulo de Tarso Müller $\oplus^{1}$

${ }^{1}$ Laboratory of Respiratory Pathophysiology, Respiratory Division, Dept of Medicine Federal University of Mato Grosso do Sul, Campo Grande, Brazil. ${ }^{2}$ Laboratory of Clinical Exercise Physiology and Respiratory Investigation Unit, Division of Respiratory and Critical Care Medicine, Department of Medicine, Queen's University, Kingston, ON, Canada.

Correspondence: P. de Tarso Müller, Laboratory of Respiratory Pathophysiology; Respiratory Division, Federal University of Mato Grosso do Sul, Rua Filinto Müller S/N, Vila Ipiranga, CEP:79080-090, Campo Grande, Brazil.

E-mail: paulo.muller@ufms.br

Received: Dec 112016 | Accepted after revision: Jan 112017

Conflict of interest: None declared.

\section{References}

1 Owens GR, Rogers RM, Pennock BE, et al. The diffusing capacity as a predictor of arterial oxygen desaturation during exercise in patients with chronic obstructive pulmonary disease. N Engl J Med 1984; 310: 1218-1221.

2 Kirby M, Owrangi A, Svenningsen S, et al. On the role of abnormal DL(CO) in ex-smokers without airflow limitation: symptoms, exercise capacity and hyperpolarised helium-3 MRI. Thorax 2013; 68: 752-759.

3 Elbehairy AF, Guenette JA, Faisal A, et al. Mechanisms of exertional dyspnoea in symptomatic smokers without COPD. Eur Respir J 2016; 48: 694-705.

4 Soumagne T, Laveneziana $\mathrm{P}$, Veil-Picard $\mathrm{M}$, et al. Asymptomatic subjects with airway obstruction have significant impairment at exercise. Thorax 2016; 71: 804-811.

5 Tan WC, Sin DD, Bourbeau J, et al. Characteristics of COPD in never-smokers and ever-smokers in the general population: results from the CanCOLD study. Thorax 2015; 70: 822-829.

6 Hueper K, Vogel-Claussen J, Parikh MA, et al. Pulmonary Microvascular Blood Flow in Mild Chronic Obstructive Pulmonary Disease and Emphysema. The MESA COPD Study. Am J Respir Crit Care Med 2015; 192: 570-580.

7 Ofir D, Laveneziana P, Webb KA, et al. Mechanisms of dyspnea during cycle exercise in symptomatic patients with GOLD stage I chronic obstructive pulmonary disease. Am J Respir Crit Care Med 2008; 177: 622-629.

8 Chin RC, Guenette JA, Cheng S, et al. Does the respiratory system limit exercise in mild chronic obstructive pulmonary disease? Am J Respir Crit Care Med 2013; 187: 1315-1323.

9 Elbehairy AF, Ciavaglia CE, Webb KA, et al. Pulmonary gas exchange abnormalities in mild chronic obstructive pulmonary disease. implications for dyspnea and exercise intolerance. Am J Respir Crit Care Med 2015; 191: 1384-1394.

10 Davis C, Sheikh K, Pike D, et al. Ventilation heterogeneity in never-smokers and COPD: comparison of pulmonary functional magnetic resonance imaging with the poorly communicating fraction derived from plethysmography. Acad Radiol 2016; 23: 398-405.

11 Gläser S, Ittermann T, Koch B, et al. Influence of smoking and obesity on alveolar-arterial gas pressure differences and dead space ventilation at rest and peak exercise in healthy men and women. Respir Med 2013; 107: 919-926.

12 Hirsch GL, Sue DY, Wasserman K, et al. Immediate effects of cigarette smoking on cardiorespiratory responses to exercise. J Appl Physiol 1985; 58: 1975-1981.

13 Montes de Oca M, Loeb E, Torres SH, et al. Peripheral muscle alterations in non-COPD smokers. Chest 2008; 133: 13-18. 
14 Wüst RCI, Morse CI, de Haan A, et al. Skeletal muscle properties and fatigue resistance in relation to smoking history. Eur J Appl Physiol 2008; 104: 103-110.

15 Gläser S, Obst A, Opitz CF, et al. Peripheral endothelial dysfunction is associated with gas exchange inefficiency in smokers. Respir Res 2011; 12: 53.

Copyright @ERS 2017 